\title{
COMUNICAÇÕES
}

\section{Efeito de pesticidas no crescimento micelial de Cercospora caricis}

\author{
Zilá Ribeiro de Ávila'; Sueli Correa Marques de Mello ${ }^{1}$
}

\begin{abstract}
'Embrapa Recursos Genéticos e Biotecnologia.<zribeirodeavila@yahoo.com.br>; <smello@cenargen.embrapa.br> Autor para correspondência: Zilá R. de Ávila. <zribeirodeavila@yahoo.com.br>

Data de chegada: 05/01/04. Aceito para publicação em: 25/10/04.
\end{abstract}

Microrganismos fitopatogênicos são instrumentos valiosos em programas de manejo de plantas daninhas e devem ser pesquisados especialmente para espécies como Cyperus rotundus L.(tiririca), para a qual não existe um método de controle eficaz. O uso destes agentes associados a outras práticas de controle, com certeza, possibilitará ao agricultor reduzir as perdas na produção agrícola e ao mesmo tempo minimizar os danos causados ao meio ambiente. $\mathrm{O}$ fungo Cercospora caricis, foi detectado no Brasil infectando plantas de tiririca. Vários estudos foram conduzidos na Embrapa Recursos Genéticos e Biotecnologia com este patógeno, a fim de avaliar a sua infectividade e especificidade de hospedeiros. Os resultados obtidos foram promissores, indicando que o mesmo apresenta potencial para ser utilizado como agente no controle biológico da tiririca. Neste sentido, o presente trabalho, foi realizado, com o objetivo de avaliar o efeito de pesticidas utilizados tanto para o controle da tiririca, quanto das doenças e pragas das culturas associadas a esta espécie daninha, sobre o crescimento micelial de Cercospora caricis Oudemans.

Os pesticidas utilizados foram: Benomyl, Cerconil, Oxicloreto de Cobre (fungicidas), Oxifluorfen, Chlorimuron-ethyl, Glifosato (herbicidas) e Metil demetom (inseticida/acaricida). As concentrações avaliadas dos produtos, foram: 0 (testemunha), 1, 10,100 e $1000 \mu \mathrm{g} / \mathrm{mL}$, a partir de solução estoque preparada à concentração de $10.000 \mu \mathrm{g} / \mathrm{mL}$. Discos de $4 \mathrm{~mm}$ de diâmetro, retirados de colônias de $C$. caricis com 15 dias de idade, foram transferidos para o centro de placas contendo meio de BatataDextrose-Ágar (BDA) acrescido do agrotóxico referente a cada tratamento, nas concentrações indicadas. A incubação das culturas se deu a $25{ }^{\circ} \mathrm{C}$, sob fotoperíodo de 12 horas. O fotoperíodo foi simulado por meio de quatro lâmpadas fluorescente de $20 \mathrm{~W}$, luz do dia, instaladas na porta da BOD (Nova Técnica, modelo NT 708-AT). Adotou-se o delineamento experimental inteiramente casualizado, com três repetições, cada placa representando uma parcela. Foram tomadas medidas do diâmetro das colônias a partir do sétimo dia de incubação. Os valores obtidos nas diversas leituras foram usados para cálculo da Área Abaixo da Curva de Crescimento (AACC), utilizando o programa AVACPD, para maior precisão dos resultados.

A inibição do crescimento micelial do patógeno ocorreu em presença dos pesticidas Benomyl, Metil demetom e Cerconil, nas concentrações de $100 \mu \mathrm{g} / \mathrm{mL}$ e $1000 \mu \mathrm{g} / \mathrm{mL}$, indicado pelos me- nores valores da AACC (Figura 1). Com Oxyfluorfen, Chlorimuron-ethyil e Glifosato, só houve inibição com a concentração de $1.000 \mu \mathrm{g} / \mathrm{mL}$. Oxicloreto de Cobre não inibiu o crescimento de $C$. caricis, em nenhuma das concentrações utilizadas. Estes resultados indicam a possibilidade da utilização conjunta do isolado CG672 de $C$. caricis com o Oxicloreto de cobre, independentemente da concentração deste produto; com os herbicidas Glifosato, Oxyfluorfen e Chlorimuron-ethyl, a concentrações de até $100 \mu \mathrm{g} / \mathrm{mL}$ e com os demais produtos em concentrações inferiores a $100 \mu \mathrm{g} / \mathrm{mL}$. Os dados obtidos servirão de base para outros trabalhos visando, no futuro, à implementação de uma estratégia de manejo integrado da tiririca, que deverá incluir liberações inundativas de $C$. caricis.

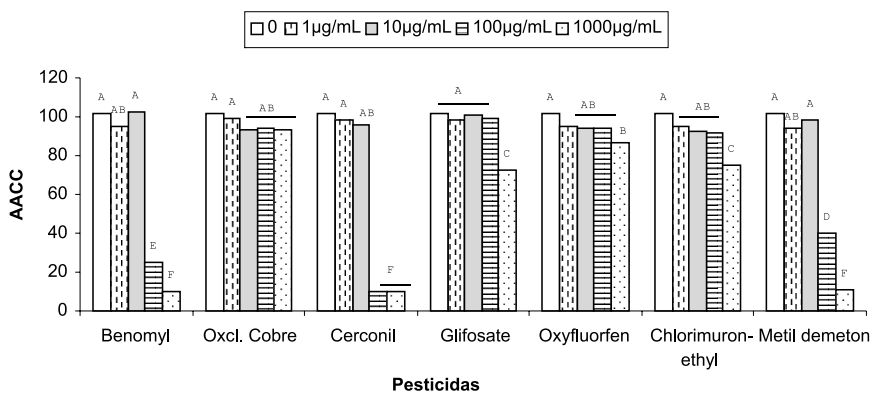

Figura 1- Efeito de pesticidas no crescimento micelial de Cercospora caricis. Barras referidas de mesma letra não diferiram significativamente entre si, pelo teste de Duncan, a 5\% de probabilidade 